February 2004

\title{
Measuring and improving health care quality: nursing's contribution to the state of science
}

\author{
Doris C. Vahey \\ Mt. Sinai Medical Center, NY and New York University \\ Beth Ann Swan \\ Thomas Jefferson University \\ Norma M. Lang \\ University of Pennsylvania \\ Pamela H. Mitchell \\ University of Washington
}

Follow this and additional works at: https://jdc.jefferson.edu/nursfp

Part of the Nursing Commons

Let us know how access to this document benefits you

\section{Recommended Citation}

Vahey, Doris C.; Swan, Beth Ann; Lang, Norma M.; and Mitchell, Pamela H., "Measuring and improving health care quality: nursing's contribution to the state of science" (2004). College of Nursing Faculty Papers \& Presentations. Paper 4.

https://jdc.jefferson.edu/nursfp/4

This Article is brought to you for free and open access by the Jefferson Digital Commons. The Jefferson Digital Commons is a service of Thomas Jefferson University's Center for Teaching and Learning (CTL). The Commons is a showcase for Jefferson books and journals, peer-reviewed scholarly publications, unique historical collections from the University archives, and teaching tools. The Jefferson Digital Commons allows researchers and interested readers anywhere in the world to learn about and keep up to date with Jefferson scholarship. This article has been accepted for inclusion in College of Nursing Faculty Papers \& Presentations by an authorized administrator of the Jefferson Digital Commons. For more information, please contact: JeffersonDigitalCommons@jefferson.edu. 


\title{
Measuring and improving health care quality: Nursing's contribution to the state of science
}

\author{
Doris C. Vahey, PhD, RN \\ Beth Ann Swan, PhD, CRNP \\ Norma M. Lang, PhD, RN, FAAN, FRCN \\ Pamela H. Mitchell, PhD, RN, FAAN
}

Doris C. Vahey is a Project Coordinator at The Mount Sinai Medical Center, New York, and an Adjunct Professor at New York University, New York, NY.

Beth Ann Swan is an Associate Director in the Office of International Programs, University of Pennsylvania School of Nursing, Philadelphia, PA.

Norma M. Lang is the Lillian S. Brunner Professor of Nursing at the University of Pennsylvania School of Nursing, Philadelphia, PA.

Pamela H. Mitchell is the Elizabeth S. Soule Professor at the School of Nursing, University of Washington, Seattle, WA.

The Conference was dedicated to John Eisenberg, the late director of AHRQ and former chief of the Division of Internal Medicine at the University of Pennsylvania. Reprint requests: Dr. Norma M. Lang, 420 Guardian Drive, Room 365, Philadelphia, PA 19104.

E-mail: nlang@nursing.upenn.edu

Concern over the quality of health care is a recurring topic in the United States. A "state of the science" invitational conference on quality health care, titled "Measuring and Improving Health Care Quality, Towards Meaningful Solutions To Pressing Problems, Nursing's Contribution to the State of the Science" was held April 18-20, 2002 in Philadelphia at the Annenberg Center for Public Policy, University of Pennsylvania. This conference stemmed from the work of the American Academy of Nursing (AAN) Expert Panel on Quality Health Care and had its genesis in June 1996 during the AAN Expert Panel on Quality's Conference titled, "Outcome Measures and Care Delivery Systems." This conference was also responsive to recent reports published by the Institute of Medicine (IOM) and others, which have concluded that quality problems can lead to poorer health and that widespread quality problems exist throughout American medicine. ${ }^{1-8}$

\section{Conference Goals}

The conference was devoted to measuring and improving health care quality. The objectives were carried out through the presentation of working papers and discussion among expert interdisciplinary participants from nursing, health services research, policy, and communications regarding strategies for measurement, available datasets, strengths and weaknesses of different methodologies and technologies, and recommendations for further development. 
The focus on measuring and improving health care quality was directly linked to the Agency for Healthcare Research and Quality (AHRQ) mission to enhance the quality, appropriateness, and effectiveness of health services. To date 4 of the 5 specific aims of the conference have been met as follows: (1) A state-of-the-science research "working" quality conference was conducted; (2) methodological and technical issues surrounding the definition and measurement of nursing care quality in order to strengthen quality measurement and improvement were identified; (3) resources available such as secondary data sources for research and benchmarking were identified; and (4) recommendations for research and health policy were developed. The fifth specific aim is underway, to disseminate conference findings to organizations and individuals that have the capability to use the information in order to advance research and increase public visibility to improve the quality of health care services.

\section{Opening Panel}

The two and a half day conference began with a provocative panel discussion "Keeping Health Care Quality on the Policy Agenda", moderated by Kathleen Hall Jamieson, PhD, Dean, Annenberg School for Communication, University of Pennsylvania. The panel was co-sponsored by the Leonard Davis Institute for Health Economics (LDI) at the University of Pennsylvania. National experts presented their views on how to focus and keep public attention on issues of health care quality. The panel was constructed to provide perspectives of payers/insurers, health professionals/providers, and recipients/consumers. The distinguished members of the panel included: Trudy Lieberman, Senior Health Policy Editor of Consumer Reports; Gregg Meyer, MD, Director of the Center for Quality Improvement and Patient Safety, AHRQ; Dennis O'Leary, MD, President of the Joint Commission on Accreditation of Healthcare Organizations (JCAHO); and Kenneth Shine, MD, President, Institute of Medicine (IOM).

Key issues raised during the panel presentation and discussion included:

- The need to compile data and translate them into useful information for consumers;

- The ability to gain attention and motivate action by presenting evidence that is compelling and that people can relate to (eg, the IOM report on patient safety);

- The notion that the provision of high quality and safe care is a system issue and not just the responsibility of any one part of the health care sector, but rather, everyone's job;

- The identification of barriers to quality improvement—such as a lack of standardized measures, inadequate information systems to collect data, inadequate resources to pay for data collection and translation, and technological issues;

- The need to make a business case for providing quality care (ie, high quality pays);

- The need for a new communications strategy about quality, one that would invent a new vocabulary that would be meaningful for discussing the issues;

- The need to consider how quality improvement strategies "trickle down" to affect clinical care;

- The idea that ultimately quality is a product of local and individual decisions; and 
- The premise that for most Americans care is quite good, and that bringing those that have little or no access to health care, such as the uninsured, into the system we have now, would have a much bigger impact on overall quality than the current focus.

Consumers, providers, and politicians must first care about quality as an issue before any changes can be made to improve it. Additionally, quality of care is a systemic concern and no one group or intuition should be responsible for maintaining and/or improving it. Finally, changes in many areas simultaneously (eg, measurement, translation, access to care, etc) will ultimately have the greatest impact on improving quality.

\section{Working Papers}

The momentum and enthusiasm gained from the opening discussion continued throughout the following nine working sessions, each with a moderator and recorder. The more than 40 invited experts submitted a total of 24 papers prior to the conference so that each would have had the opportunity to read the other's work and provide critical feedback during the working sessions. The authors, therefore, used the conference time to present a brief overview highlighting their relevant issues and key recommendations for policy, practice, and research. The papers were designed to meet the objectives of the conference and address six key questions:

1. What is known about nursing's contribution to quality across the health care continuum including setting and system level issues?

2. What is known about health outcomes, quality of nursing care, and staffing through linking indicators, databases, and organizational characteristics?

3. What do consumer, nurse, and physician assessment of quality tell us about the quality of care?

4. What is the status, methodologies, and challenges of quality indicators measured within large databases (eg, Healthcare Cost and Utilization Project (HCUP), Conquest, Outcome and Assessment Information Set (OASIS), Minimum Data Set (MDS), Resident Assessment Instrument (RAI), American Nurses Association (ANA) Clinical Indicators)?

5. What can be learned about nursing practice frombest practices, evidence-based care centers, and studies of variation in the use of health care services?

6. What are the policy, practice and service, and research recommendations?

Selected articles that addressed these questions are included in this Nursing Outlook Supplement. Other selected papers are included in a Medical Care Supplement. ${ }^{10}$

\section{Articles Included in this Issue}


The Supplement begins with acknowledging that a critical need exists for resources, both conceptual and methodological, from which health professionals can draw information for decisions about health care quality. A growing body of health care knowledge has been generated through scientific inquiry and systematically analyzed and categorized for clinician use. $^{11-12}$

Mark, Hughes, and Jones explore the problems that result from the absence of a strong theory to guide research relevant to quality and patient safety. Understanding that appropriate theoretical conceptualization will optimally drive research investigating quality of care and patient safety, researchers must also contend with the demands associated with data management. These include identifying appropriate sources of data, acquiring the relevant data sets, matching the required data elements with the data elements available in the data set, examining their reliability and validity, and then, finally, integrating the data into the overall research project. ${ }^{13-15}$

The following three articles address these demands. While many nurses/health services researchers are familiar with sources of data for hospitalized acutely ill patients, less well known are sources of data for non-acute and long-term care settings. The first two articles, by Rantz and Connelly and by Ryan, Stone and Raynor, identify and evaluate several large data sets widely used in long-term care research. The next article describes issues related to matching required data elements with available data elements, and the benefits that can result for improving quality for patients when clinical data and best practices are integrated. Dunton, Taunton and Moore describe some of the issues they faced in using the American Nurses' Association National Database of Nursing Quality Indicators to evaluate the relationship between nurse staffing and patient falls.

Overall, these authors recognize that core quality indicators linking care across settings need to be developed. This includes the conceptualization and operationalization of key performance measures, as well as identification of nursing-sensitive measures in the realm of the "traditional" structure, process, and outcome variables. ${ }^{16}$ Finally, all participants noted the need for improved risk adjustment methodologies.

The next article provides an overview of the state of the science, both in research and actions taken, in an effort to discover and measure what system and work environment factors must change to improve outcomes for health care providers and consumers. Brooten et al. describe the effects of the advanced practice nurse (APN) workforce on quality as reflected in patient outcomes and health care costs and APN dose effect within the context of the current quality indicator quagmire.

Improving the quality of health care will require a complex blend of strategies for practice, research, and policy. No area will remain untouched or unchanged. At the same time that we attempt to capitalize on emerging research, it is essential to look for opportunities to go down new and untested paths. The final two articles look to the past and the future to set immediate priorities for advancing the nation's health care quality agenda. The authors highlight changes in practice, science, and national policy that are needed to achieve quality goals. 
Jennings and McClure describe the significant benefits to be gained from expanding current thinking about quality. They propose new strategies that will move the quality debate into a more effective position to achieve desired outcomes. Lamb, Jennings, Mitchell, and Lang synthesize the recommendations of each of the articles presented in this supplement and the collective dialogue of the authors into specific strategic priorities for action. Weaving together the state of the science with the urgent call for action, they lay out a blueprint for moving forward.

\section{Recommendations}

There was recognition of the significant strides in quality research on nursing's contribution to quality health care since the 1996 American Academy of Nursing quality conference. For example, some research has addressed the recommendations set forth at the June 1996 Invitational Conference, ${ }^{24}$ which included: (1) Developing, explicating, and testing theory about the assumed causal relations between the structure and process variables and the related health outcome variables; ${ }^{17-23,25-29}$ (2) encouraging creative strategies to utilize existing primary and secondary data sets to generate control or comparison groups and to conduct outcomes research; ${ }^{30-35}$ (3) capitalizing on natural experiments that change structures or processes to test theory about causal or interactive relations among organizational factors and outcomes; (4) increasing expertise in methodological issues unique to organizational research; ${ }^{36-39}$ and (5) refining selected outcome categories. ${ }^{40-42}$

However, despite the progress made, there is urgent need for further research, especially in view of the dramatic changes in health care delivery and the expanded care provider roles of nurses in a variety of settings. Throughout the two and a half days, spirited discussions led to the identification of several priority areas for a unified practice, policy, and research agenda. Strategic priorities were purposely categorized according to common unifying themes, rather than along the traditional lines of practice (research and policy), to emphasize the importance of integration and collaboration among stakeholders in the quality agenda. Readers are referred to the Lamb et al article at the end of this supplement for greater details.

\section{Conclusion}

The conference offered the opportunity to review progress since 1996, as well as reflect on changes and the current status of quality in the United States (eg, what has been accomplished, what are the remaining gaps, and why a new perspective is needed to incorporate nurses' expanding roles in providing care, collaboration with other health providers and participation in non-traditional approaches to care delivery). This conference has been instrumental in identifying the broad scope of issues surrounding the delivery of quality health services, as well as the critical role that nurses play in that delivery.

Equally important is the opportunity this conference provides in helping to shape the National Health Care Quality Report (Quality Report) and subsequent annual reports, to ensure it provides a comprehensive reflection of quality that will be meaningful for patients. The first Quality Report is due to Congress in FY2003 and annually thereafter. The objectives of the report include: Enhancing awareness of quality, monitoring possible effects 
of policy decisions and initiatives, and assessing progress in meeting national goals. 5 This conference has identified the state of the science in quality and provides future directions about what needs to be done to achieve quality health outcomes.

Recommendations call for coordinated efforts between consumers, providers, purchasers, researchers, and regulators of health care services. These coordinated efforts must yield improved quality for the patient in the various settings where care is being delivered. The efforts should be aimed at maintaining the good that exists, as well as focusing on areas of the system that require improvement such as staffing, clinical and information systems, patient safety, and evaluation methods. ${ }^{17,43-49}$

The conference was funded by the Agency for Healthcare Research and Quality (AHRQ) via the small grant program for conference support (PA Number: R13 HS12058). Additional funding and support was garnered from the American Academy of Nursing (AAN), and the University of Pennsylvania's Annenberg Public Policy Center, Center for Health Outcomes and Policy Research, and the Leonard Davis Institute (LDI) for Health Care Economics. The conference leaders were Norma M. Lang and Pamela Mitchell. The Steering Committee also included Ada Sue Hinshaw, Bonnie Jennings, Gerri Lamb, Barbara Mark, Patricia Moritz and two postdoctoral research fellows Beth Ann Swan and Doris C. Vahey.

\section{References}

1. Chassin MR, Galvin RW, and the National Roundtable on Health Care Quality. The urgent need to improve health care. JAMA 1998;280:1000-05.

2. Institute of Medicine. The National Roundtable on Health Care Quality: Measuring the quality of health care. Washington, DC: National Academy Press; 1999.

3. Institute of Medicine. To err is human: Building a safer health system. Washington, DC: National Academy Press; 1999.

4. Institute of Medicine. Crossing the Quality Chasm: A New Health System for the 21st Century. Committee on Quality of Health Care in America. Washington, D.C.: National Academy Press; 2001.

5. Institute of Medicine. Envisioning the National Health Care Quality Report. Washington, DC: National Academy Press; 2001.

6. Joint Commission on Accreditation of Healthcare Organizations (JCAHO). http://www.jcaho.org/aboutjc/facts.html.

7. Leapfrog Group. http://www.leapfroggroup.org/-consortium of Fortune 500 companies and other large private and public health care purchasers sponsored by the Business Roundtable that are working together to drive improvements in patient 
safety.

8. President's Advisory Commission on Consumer Protection and Quality in the Health Care Industry. Quality first: Better health care for all Americans. Available at: http://www.hcqualitycommission.gov/final/.

9. Weiner J. Leonard David Institute (LDI) Health Policy Seminar Series. (April 2002). Keeping health care quality on the policy agenda. Available at: http://www.upenn.edu/ldi/panel.html.

10. Medical Care Supplement. 2004;42.

11. Mitchell PH, Lang NM. Framing the problem of measuring and improving health care quality: Has the quality health outcomes model been useful? Med Care 2004;42:II4-11.

12. Swan BA, Boruch RF. Quality of evidence: Usefulness in measuring the quality of health care. Med Care 2004;42: II12-20.

13. Bakken S, Cimino J, Hripcsak G. Promoting patient safety and enabling evidencebased practice through informatics. Med Care 2004;42:II49-56.

14. Maas M, Delaney C. Nursing process outcome linkage research: Issues, current status, and health policy implications. Med Care 2004;42:II40-8.

15. Weiner M, Long J. Cross-sectional versus longitudinal performance assessments in the management of diabetes. Med Care 2004;42:II34-9.

16. Donabedian A. Evaluating the quality of medical care. Milbank Memorial Fund Quarterly 1966;44:166-206.

17. Aiken LH, Clarke SP, Sloane DM, et al. Nurses' reports on hospital care in five countries. Health Affairs 2001;20:43-53.

18. Aiken LH, Clarke SP, Sloane DM, et al. Hospital nurse staffing and patient mortality, nurse burnout, and job dissatisfaction. JAMA 2002;288:1987-93.

19. Aiken LH, Clarke SP, Sloane DM. Hospital restructuring: Does it adversely affect care and outcomes. J Nurs Admin 2000;30:457-65.

20. Aiken LH, Sloane D, Sochalski JA. Hospital organization and outcomes. Qual Health Care 1998;7:222-26.

21. Mattke S, Needleman J, Buerhaus P. Evaluating the role of patient sample definitions for quality indicators sensitive to nurse staffing patterns. Med Care 2004;42:II21-33. 
22. Sochalski J. Is more better? The relationship between nurse staffing and the quality of nursing care in hospitals. Med Care 2004;42:II67-73.

23. Vahey DC, Aiken LH, Sloane DM, et al. Nurse burnout and patient satisfaction. Med Care 2004;42:II57-66.

24. Mitchell PH, Heinrich J, Moritz P, et al. Outcome measures and care delivery systems: Introduction and purposes of conference. Med Care 1997;35:NS1-5.

25. Blegen MA, Goode CJ, Reed L. Nurse staffing and patient outcomes. Nurs Research 1998;47:43-50.

26. Gittell JH, Fairfield KM, Bierbaum B, et al. Impact of relational coordination on quality of care, postoperative pain and functioning, and length of stay: A ninehospital study of surgical patients. Med Care 2000;38:807-19.

27. Irvine D, Sidani S, Hall L. Linking outcomes to nurses' roles in health care. Nurs Econ 1998;16:58-64, 87.

28. Mitchell P, Ferketich S, Jennings B, et al. Quality health outcomes model. Image: The J Nurs Schol 1998;30:43-6.

29. Shortell S, Jones R, Rademaker A, et al. Assessing the impact of total quality management and organizational culture on multiple outcomes of care for coronary artery bypass graft surgery patients. Med Care 2000;38:207-17.

30. American Nurses Association. Implementing nursing's report card: A study of RN staffing, length of stay, and patient outcomes. Washington, DC: American Nurses Publishing; 1997.

31. American Nurses Association. Nursing staffing and patient outcomes in the inpatient hospital setting. Washington, DC: American Nurses Publishing; 2000.

32. Kovner C, Gergen P. Nurse staffing levels and adverse events following surgery in U.S. hospitals. Image: J Nurs Schol 1998;30:315-21.

33. Lawthers A, McCarthy E, Davis R, et al. Identification of in-hospital complications from claims data. Is it valid? Med Care 2000;38:785-95.

34. Needleman J, Buerhaus P. Nurse staffing and patient outcomes in hospitals. Final Report for Health Resources Services Administration Contract No. 230-99-0021. 2001.

35. Weingart S, Iezzoni L, Davis R, et al. Use of administrative data to find substandard care: Validation of the complications screening program. Med Care 2000;38:796-806. 
36. McCarthy E, Iezzoni L, Davis R, et al. Does clinical evidence support ICD-9-CM diagnosis coding complications? Med Care 2000;38:868-76.

37. Peabody J, Luck J, Glassman P, et al. Comparison of vignettes, standardized patients, and chart abstraction: A prospective validation study of three methods for measuring quality. J Am Med Assoc 2000;283:1715-22.

38. Pearson M, Lee J, Chang B, et al. Structured implicit review: A new method for monitoring nursing care quality. Med Care 2000;38:1074-91.

39. Rubenstein L, Mittman B, Yano E, et al. From understanding health care provider behavior to improving health care: The QUERI framework for quality improvement. Quality Enhancement Research Initiative. Med Care 2000; 38:1129-41.

40. American Nurses Association. Nursing quality indicators beyond acute care: Literature review. Washington, DC: American Nurses Publishing; 2000.

41. American Nurses Association. Nursing quality indicators beyond acute care: Measurement instruments. Washington, DC: American Nurses Publishing; 2000.

42. HCUP Patient Safety Indicators, 2002.

43. Becher EC, Chassin MR. Improving quality, minimizing error: Making it happen. Health Affairs 2001;20:68-81.

44. Blendon RJ, Kim M, Benson JM. The public verses the World Health Organization on health system performance. Health Affairs 2001;20:10-20.

45. Buerhaus $P$, Needleman J. Policy implications of research on nurse staffing and quality of patient care. Policy, Politics, Nurs Pract 2000;1:5-16.

46. Buerhaus P, Needleman J. Policy responses to an aging registered nurse workforce. Nursing Economics 2000;18: 278-284.

47. Fagin CM. When care becomes a burden: Diminishing access to adequate nursing. Milbank Memorial Fund Report. 2001. New York, NY: Milbank Memorial Fund; 2001.

48. Foley M. Let's practice armed with the evidence. The American Nurse. 2001; May/June:4.

49. McGlynn EA, Brook RH. Keeping quality on the policy agenda. Health Affairs 2001;20:82-90. 